\title{
Bumiputera Graduate Entrepreneurs in Describing Social Status and Their Social Status Attainment Experience
}

\author{
Nur Liyana Yasmin Mohd Razalli(iD), Mohd Ali Bahari Abdul Kadir² iD \\ 1Faculty of Business and Management, Universiti Teknologi MARA (UiTM), 40450, Shah Alam, \\ Selangor, Malaysia. \\ Email: nurliyanayasmin@gmail.com \\ ${ }^{2}$ Faculty of Business and Management, Universiti Teknologi MARA (UiTM), 42300, Puncak Alam, \\ Selangor, Malaysia. \\ Email: mohda419@uitm.edu.my
}

\section{CORRESPONDING}

AUTHOR (*):

Nur Liyana Yasmin Mohd

Razalli

(nurliyanayasmin@gmail.com)

\section{KEYWORDS:}

Social Status

Bumiputera

Graduate

Entrepreneurs

\section{CITATION:}

Nur Liyana Yasmin Mohd Razalli \& Mohd Ali Bahari Abdul Kadir. (2022). Bumiputera Graduate Entrepreneurs in Describing Social Status and Their Social Status Attainment Experience. Malaysian Journal of Social Sciences and Humanities (MJSSH), 7(2), e001302.

https://doi.org/10.47405/mjssh.v7i2.1302

\begin{abstract}
Social status is essential to every individual whether they may or may not be aware of it and admit the importance of social status in their lives. Even in the case of Bumiputera graduates entrepreneurs, they acknowledged that social status is beneficial in businesses although some of them were reluctant to admit the importance of social status. That is not surprising because the Bumiputera has a culture of communicating indirectly. Being too honest is considered insensitive or rude. Interviews with seven Bumiputera graduate entrepreneurs in Klang Valley found that they have other ways to describe social status. To them, social status represents their view of themselves, their feeling of satisfaction, and the attention given to them. These elements change according to their achievements or failures in their lives. The model of social status attainment experience by the Bumiputera graduate entrepreneurs is also illustrated in this paper.
\end{abstract}

Contribution/Originality: This study contributes to the existing social status literature. The paper's primary contribution is finding that social status represents the Bumiputera graduates' view of themselves, their feeling of satisfaction, and the attention given to them. The results contribute to the government's effort in encouraging more Bumiputera graduates to become entrepreneurs.

\section{Introduction}

Entrepreneurship is the process of creating a commercial enterprise or new company with a high potential to expand, usually in an industry or sector of the economy (Encyclopedia, 2020). One of the opportunities for the emergence of entrepreneurs is a developing economy. A developing economy provides prospects for individuals seeking the chance to create new firms, grow existing businesses, allow new businesses to 
replace the old ones, and innovate something that has never been discovered before (Mahadea \& Kaseeram, 2018). These opportunity entrepreneurs are pulled to achieve higher personal satisfaction, earn more wealth, and make employment opportunities available to others (Mersha et al., 2010). They will grab the opportunity in the market they want to pursue (Garcia-Lorenzo, 2018). In terms of developing the economy, they receive more attention because it is likely for their business to grow and benefit the economy (Jha, 2016).

The good in the bad, local unemployment rates also promotes entrepreneurship startups (Fairlie \& Fossen, 2018), especially among the graduates. They are expected to get employment opportunities effortlessly and occupy high-level positions after completing their studies because people assume they should be more competent than those with lower academic qualifications (Abdullah, 2018; Bartos et al., 2015). But it is not necessarily true as some of them are unable to find employment opportunities. Entrepreneurship has been found as a survival mechanism due to the lack of employment opportunities (Brewer \& Gibson, 2014; Garcia-Lorenzo, 2018; Mahadea \& Kaseeram, 2018; Mersha et al., 2010). But that is just that. The desperation and the desire to fulfil needs are still not strong enough to promise successful businesses (Mcewan, 2020). They have low productivity and are not very innovative (Jha, 2016). Only a few of them can sustain their business, and evolve as established, successful entrepreneurs (Mersha et al., 2010) hence invisible to policymakers and academic researchers (Garcia-Lorenzo, 2018).

However, both conditions mentioned above still do not appear to be solid reasons for the graduates in Malaysia to become entrepreneurs. Department of Statistics Malaysia (2021) found that 16,000 out of 202400 unemployed graduates in Malaysia were already unemployed for more than a year. The government has provided them with training programmes and financial aid, but they did not become entrepreneurs. Indeed, the emergence of entrepreneurs is not significantly influenced by the structure of economic incentives (Hamilton \& Harper, 1994). Hence, apart from changing society's mindset, Razalli \& Kadir (2021) suggested that the government needs to take the initiative in understanding a particular individual's or society's sociological background. The background provides intellectual values in entrepreneurship by understanding human society and the social system (Hamilton \& Harper, 1994; Mondal, 2017), making entrepreneurial activities more predictable (Reynolds, 1992). This paper discusses the findings from interviews with seven Bumiputera graduate entrepreneurs in the Klang Valley.

\section{Literature Review}

Entrepreneurship is a cross-disciplinary concept and has been the concentration of research in various disciplines like the economy, management, psychology, and sociology (Hodzic, 2016). The reason for any individuals to set up their own business varies and is well-argued and has been the fundamental priority of entrepreneurial thoughts and theories (Akpor-Robaro, 2012). However, most research on entrepreneurship in Malaysia is limited to the same theoretical background, methodology, and samples (Abdullah \& Yaacob, 2018). Thus it is unsurprising that financial assistance and training programmes are the only government's well-known efforts to encourage graduates' involvement in entrepreneurship. They seem to forget that the individuals have other reasons to start their business journey besides money, freedom, flexibility, and family support (Gabriel, 2014; Marzuki et al., 2016; Tackey \& 
Perryman, 1999), and the fact that nobody will become entrepreneurs without a solid reason (Amaran, 2015).

Occupational status is one of the important factors to be considered when choosing an occupation (Fershtman et al., 1996) because it symbolises the relative prestige, honour, standing, and esteem of any individual's occupation (Mirowsky \& Ross, 2003). The valuable contributions by the scholar of status in understanding entrepreneurial phenomena (Milanov, 2015) may be more helpful for the Ministry of Education Malaysia's (MoE's) to achieve their objective in encouraging university graduates to become entrepreneurs (Ministry of Education Malaysia, 2019). Social status is an individual's position in society attached to honour or prestige (Encyclopedia Britannica, 2019), and it is one of the important social factors in indicating any individuals to become entrepreneurs (Rokhman \& Ahamed, 2015). One of the plausible reasons for that is having a business can improve one's social status. If the main aim is to improve their social status, they will become entrepreneurs (Gabriel, 2014; Rokhman \& Ahamed, 2015). Individuals with a fundamental desire for social status will be driven to react strongly when others perceive they have low social status (Anderson et al., 2015).

Presenting a positive image of entrepreneurship as a favoured occupation is important (Ngah et al., 2016) to make it an acceptable occupation in society. In Finland, the entrepreneurs are highly valued social status, regardless of the economic successes of the businesses (Wahlbeck, 2008). In Germany, although the entrepreneurs consider themselves as extremely serious individuals with a significant contribution to lead the economy and the society, the society has a contradicted opinion and does not take the entrepreneurs seriously (Kalden et al., 2017). Meanwhile in Malaysia, although $69.9 \%$ of the adult population thought entrepreneurs have high social status, the entrepreneurial intention was only 17.6\% (Global Entrepreneurship Research Association, 2018). In 2019 , the Bumiputera owned only $40 \%$ of almost one million companies registered under Suruhanjaya Syarikat Malaysia (SSM) (Bernama, 2019).

On that note, it seems that the Malaysians, especially the Bumiputera are tied to different standards and expectations. They belong to a society with a culture of working for others (Razalli \& Kadir, 2021) and are selective about their occupational choice. Entrepreneurship is not the preferred career choice among them as they are conscious about the opinions of others regarding their actions and appearances and concerned with status. Instead, the Bumiputera often encourage their children to become public servants or professionals (Hamidon, 2009). Social positions or occupations requiring high speciality and high authority are ranked as having the highest status (Abdollahyan \& Nayebi, 2009). Indeed, social status is essential to every individual (Anderson et al., 2015). Only that, they may or may not be aware of it and admit the importance of social status in their lives (Mohammed, 2016). Even in the case of Bumiputera graduates entrepreneurs, they acknowledged that social status is beneficial in businesses although some of them were reluctant to admit the importance of social status (Razalli \& Kadir, 2021).

That is not surprising because the Bumiputera has a culture of communicating indirectly. After all, they consider it is insensitive or rude for being too honest (Kennedy \& Mansor, 2000). This paper suggests that the Bumiputera has other ways to describe status. Furthermore, most literature does not provide details on what attaining or losing social status means to the individuals seeking, experiencing, or losing their social status. Besides, what can actually impact their social status? This paper discusses the data 
extracted from the interviews with seven Bumiputera graduate entrepreneurs in Klang Valley. The model of social status attainment experience by the Bumiputera graduate entrepreneurs is also illustrated in this paper.

\section{Methodology}

The researcher identified and interviewed seven Bumiputera graduates through purposive and snowball sampling techniques. To ensure the participants' anonymity, the researcher has assigned codes from P1 to P7the participants.

As depicted in Table 1, all the participants were males. Two of them were 40 to 49 years old, while the rest were between 20 to 29 years old when the interviews were conducted. Four of them were married, and three of them were single. Four of the participants had Degree's qualifications, while the rest had Diploma's qualifications. Five of the participants were initially from Klang Valley, and the other two participants were originally from outside Klang Valley.

Table 1: Demographic of The Participants

\begin{tabular}{lllll}
\hline Participant & Gender & Age & Marital Status & Qualification \\
\hline P1 & Male & $40-49$ & Married & Degree \\
P2 & Male & $20-29$ & Married & Diploma \\
P3 & Male & $20-29$ & Married & Degree \\
P4 & Male & $20-29$ & Single & Diploma \\
P5 & Male & $20-29$ & Single & Degree \\
P6 & Male & $20-29$ & Single & Degree \\
P7 & Male & $40-49$ & Married & Diploma \\
\hline
\end{tabular}

The study has employed semi-structured interviews with open-ended questions meant to attain views and opinions from the participants (Creswell, 2009). These questions permit the participants to respond in their own words instead of making it obligatory for them to select predetermined answers, which are sometimes unnecessarily extraneous. Open-ended questions can persuade feedbacks that are unexpected by the researcher. The feedback has meanings, is usually culturally relevant to the person, and is solid and explanatory (Mack et al., 2005). The researcher used a list of questions to guide the most significant part of the interviews. The semi-structured format has allowed the researcher to respond to the participants' emerging worldview and new ideas on the topic when collecting or analysing data (Merriam, 2009). The researcher transcribed, coded, and analysed the collected rich data using NVivo software.

\section{Result}

Interesting five themes emerged when the researcher asked the participants to describe their social status in various life experiences such as when becoming graduates, during unemployment, and others. The participants described social status as the view of oneself, feelings of satisfaction, and getting attention.

\subsection{View of Oneself}


The participants often describe social status as their view of themselves. When P2 became a graduate, he did not have the confidence and was afraid to get involved with society because, at that time, he did not have any particular directions in life.

"It [social status] was ordinary at that time because I was still a person who's searching for a direction. So not that confident, like was afraid to [get involved with] the society..."-P2

Once more, P2 noted he was not confident of meeting people when he was unemployed. His self-confidence was low, and he was afraid that others would think negatively of him for being unemployed.

"Was down at that time. Like I said, I was a bit sensitive. I always felt that other people thought that I would finish off my parents' money...Was not so confident of meeting people..."-P2

Furthermore, P2 felt 100 per cent confident of meeting other individuals and talking in public when he had a business.

"100 per cent confident. I feel more confident to be in public. I even feel confident to talk in public because I have already proved something that I can do. I have passed the level of starting a business...Now I'm in the process to expand the business. So me in the market, it's a little bit different with the people. A bit more confident."-P2

P6 shared that when he was unemployed, he thought that his social status was lower, and based on his description, he described social status as his self-esteem. He had low self-esteem when he was unemployed.

"It's [social status] definitely lower than usual because you have that feeling, like helpless, not doing anything productive. I did feel a bit useless."-P6

Some mentioned feeling proud when they completed their studies, and some felt proud when successful in having a business. For P2, he was proud merely because he had the "graduate" title.

"I was proud for a while when becoming a graduate because you're a graduate, right?"-P2

Meanwhile, P5 and P6 felt proud for completing their studies. P5 thought that the learning activity itself was not easy to do. P6 felt proud when others congratulated him for completing a challenging course.

"Felt quite proud. The Degree was not easy. Doesn't matter Degree or anything, learning is not easy."-P5

"...I feel like [the course] is something difficult, and when I finished, it's something that a lot of people congratulated me for. Feels- There's a little bit of sense of pride."-P6 
P3 noted he felt proud of becoming an entrepreneur because he could do business despite the negative things that others have said to him.

"...I feel proud of myself because able to do business. Just like that. All the time people said, "You cannot", now able to do business. "-P3

\subsection{Feelings of Satisfaction}

P6 and P1 described social status as their feelings of satisfaction when answering the researcher's questions. P6 felt quite satisfied when he graduated because he had successfully graduated. Contrarily, P1 described that he was frustrated when he was unemployed.

"But after graduating, I was quite satisfied. There's a feeling of satisfaction."-P6

"Felt frustrated. I was a little bit frustrated. Why is my life like this [unemployed]?"-P1

\subsection{Getting Attention}

When answering the researcher's question, P6 and P7 described social status as getting attention from others. P6 noted that he was sought as an idol by others for succeeding in business.

"...I felt like- many placed me as an idol. "Bro, idol. Bro, you inspired me. Anything. So I said-it's a good thing because I didn't do it for you. I actually did it for myself. But if you got [something good from] what I did for myself, that's Alhamdulillah. That's a bonus, right? I'm happy. Unexpectedly you're happy. Eh? It's good". -P1

P7 described that he felt good and happy to have many friends of various levels, and even from the high level can be contacted directly without restrictions.

"I feel good. Happy... have a lot of friends, various groups... I can mingle with artists or university directors. Meaning I can contact them directly. Meaning can straight make calls."-P7

\section{Discussion}

The graduate Bumiputera entrepreneurs' social status attainment experience follows a structure illustrated in Figure 1 below.

Figure 1: Social Status Attainment Experience

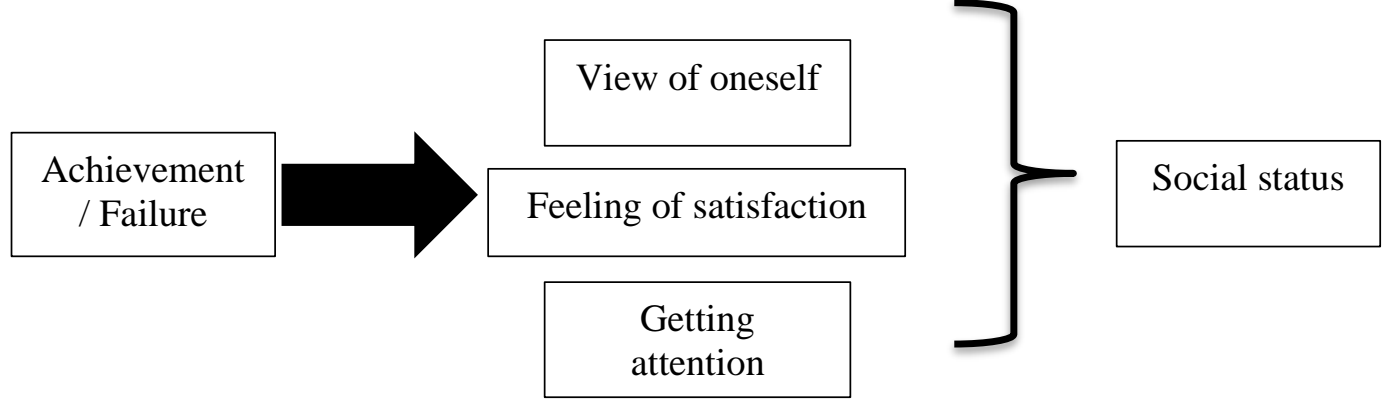


In their lives, they may face a particular achievement such as becoming a successful business owner or a failure such as failing to get employment opportunities. These lived experiences can alter their view of themselves, their feelings of satisfaction, and the attention received by them. When asked about their perceived social status, they often used these elements to describe social status. Hence, it could mean that their perceived social status is good when they have a good view of themselves, feel satisfied, and receive attention from others. It could also mean that their perceived social status is poor when they negatively view themselves, are frustrated, and do not receive attention from others.

The view of oneself differs according to their achievements or failures in life. The views include their self-confidence, self-esteem, and sense of pride. Although further understanding is required as to why one of the participants noted he was not confident when he was just a graduate, unemployment indeed can damage an individual's confidence. This is because the unemployed individuals will lose the latent functions related to employment, including establishing social status (Sarahyu \& Chung, 2017), leading to embarrassment and disorientation (Swatz, n.d.). Similar to the nature of social status, which is mobile (LibreTexts, 2021), the participant's confidence returned when his business was flourishing, which means his perceived social status was also elevated through his achievement.

Furthermore, self-confidence is one of the factors defining one's self-esteem (Cherry, 2021). Therefore, it was not surprising when on the other hand, social status meant selfesteem to another participant. Self-esteem is the individuals' global evaluation of selfworth and competence (Rose \& Vogel, 2017). Although some scholars thought it is less like social status is related to one's self-esteem (Anderson et al., 2015), individuals may develop self-esteem by meeting the cultural standards, making them feel they have meaningful and valuable lives (Brown \& Zeigler-Hill, 2017). Because the Bumiputera has a culture of working for others (Razalli \& Kadir, 2021), it could have been the plausible reason why the participant had low self-esteem when he was unemployed. His perceived social status plunged when he did not meet society's standard of becoming an employee of an organisation.

Additionally, pride is one of the critical components of a culturally universal status management system (K.Durkee et al., 2019). Some participants noted they had a sense of pride when they held the 'graduate' title, able to do things that others considered hard, like completing their studies and doing business. Pride itself means the feeling of pleasure and satisfaction from doing or having something good (Cambridge University Press, n.d.). That is also why they felt satisfied for achieving and frustrated for failing in their lives. They may have perceived that their social status was high when they got achievements and that their social status was low when they could not achieve something.

Past literature also has revealed that the size and reach of people's social networks tend to be positively related to their social status (Cao \& Smith, 2021). Having social networks and becoming well known by others may explain why social status is also referred to as a role model. Indeed, individuals with high social status are regarded as role models by society (Saputra, 2020). Meanwhiles, those who have low social status will feel less respected, besides receiving less attention from others (Anderson et al., 2015). The individual with higher status may be part of multiple social circles and therefore have more social contacts with whom to affiliate (Cao \& Smith, 2021). And 
when they have the competence or power, their respected and admired by others (Gregg et al., 2018). That is why some participants described social status as their social networks have expanded, and others have sought them as role models. Prestige and honour symbolise the social status that an individual has. It is also an individual's social position related to reputation or esteem (Pyakuryal, 2001; LibreTexts, 2021).

However, the result given in this present article is not merely to describe how the Bumiputera graduate entrepreneurs describe the social status and what elements are defining their own perceived social status. A better understanding of social status as a basic driver will allow us to harness it to guide individuals' decisions and actions to more productive paths (Anderson et al., 2015). The results may also allow the government and other interested parties to create better strategies to attract more Bumiputera, especially the Bumiputera graduates to become entrepreneurs. One of the ways can be through social status. A real entrepreneur is an individual who is generally motivated by intrinsic psychological and also economic rewards. The individual indigenously tries an entrepreneurial venture not just for personal satisfaction in work, or ego, but also status (Mukherjee, 2016) because one of the most important goals and outcomes of social life is to attain status in the groups to which we belong (Anderson et al., 2001). The government or other interested parties can use the three elements that define social status to encourage the Bumiputera graduates to become entrepreneurs. Even the necessity entrepreneurs can transit to become successful ones.

For instance, entrepreneurial motivational training can be beneficial because selfconfidence can affect entrepreneurial intention (Garaika \& Margahana, 2019; Rivai, 2012). The same goes for self-esteem (Ismail et al., 2013) because people with a positive view of themselves may feel inspired to take on new challenges (Cherry, 2021). Pride is a status-related self-conscious emotion (Bollo et al., 2018) that encourages the individual to become an entrepreneur. Pride expressions draw positive attention to one's achievements. Although it can lead to adverse outcomes such as being envied (Van Osch et al., 2019), benign envy may prompt behaviour to pursue status based on prestige as a response to a threat (Crusius \& Lange, 2017). Hence, achievement awards, or just small praises as a token of appreciation, can be given to these individuals. These efforts may spark their self-esteem, make them feel proud, and even trigger others who may be in the same boat as the entrepreneurs, like being unemployed, to achieve the same success as the existing Bumiputera graduate entrepreneurs.

Furthermore, having a social network can also encourage entrepreneurial activities because individuals can learn about the available business opportunities (Mansor \& Daud, 2020). When they have more extensive social networks and are well-known, they may become role models to others. They play essential roles (Bosma et al., 2012; Kennedy et al., 2003; Malebana, 2016; Nowiński \& Haddoud, 2018) because role models can encourage more Bumiputera to go into and succeed in business (Hamidon, 2009). Besides that, a role model significantly influences self-efficacy and belief to use his skill to achieve desired results (Garaika \& Margahana, 2019). Therefore, facilitating a way for the graduates to expand their social network may be beneficial to attract them to become one. Existing graduate entrepreneurs can act as role models for others. But the graduates must be introduced to role models with similar challenges and worries as theirs. The entrepreneurs would feel more positive and safer about their journey in entrepreneurship by sharing their same experiences (Hodzic, 2016). Lack of recognizable role models and lack of inspiration from society can hinder the positive image towards business start-ups among graduates (Shanka, 2016). 


\section{Conclusion}

To the Bumiputera graduate entrepreneurs, social status is their view of themselves, their feeling of satisfaction, and the attention given to them. These elements differ according to their achievements or failures in their lives. As that is how they describe social status, it can also mean that they may believe they have good social status when they have a good view of themselves, feeling of satisfaction, and receive attention from others. Where else, when they have a negative view of themselves, feeling frustrated, and not getting attention from others, it can mean that they are describing their poor or low social status. Social status is not entirely useless in attracting graduates to become entrepreneurs. The government and other parties interested in attracting more graduates, especially the Bumiputera, to become entrepreneurs, may use the elements defining social status as a few of the efforts. Because past literature has also found that these elements affect entrepreneurial intention, entrepreneurial motivational programmes, giving praises, and even introducing relevant role models may be beneficial. Furthermore, social status is also suitable to inspire graduates already in the entrepreneurship field to expand their businesses further and not just stay at small scales.

\section{Acknowledgement}

Part of this article was extracted from research conducted for a doctoral thesis to be submitted to Universiti Teknologi Mara, Selangor by Nur Liyana Yasmin and supervised by Assoc. Prof. Dr. Mohd Ali Bahari. Deepest gratitude to the supervisor and research participants for sharing valuable thoughts.

\section{Funding}

This study received no financial support from any parties.

\section{Conflict of Interests}

The authors declare no conflict of interest in this study.

\section{References}

Abdollahyan, H., \& Nayebi, H. (2009). Conceptualizing Occupational Prestige: An Empirical Case Study from Iran. Asian Journal of Social Science, 37, 192-207.

Abdullah, N., \& Yaacob, Z. (2018). Predicting Entrepreneurial Intention Among University Students Using Theory of Planned Behavior. ASEAN Entrepreneurship Journal (AEJ), 4(2), 158-168.

Abdullah, Z. (2018). Exploring University Branding: Employers' Expectation On University Graduates On Competency. Jurnal Personalia Pelajar, 21(1), 95-104.

Akpor-Robaro, M. O. M. (2012). The Impact of Socio-Cultural Environment On Entrepreneurial Emergence: A Theoretical Analysis of Nigerian Society. European Journal of Business and Management, 4(16), 172-183.

Amaran, M. A. (2015). Involvement of Graduates in the Field of Entrepreneurship in Kuala Lumpur, Malaysia. International Journal of Liberal Arts and Social Science., 3(9), 46-53. 
Anderson, C., Hildreth, J. A. D., \& Howland, L. (2015). Is The Desire for Status a Fundamental Human Motive? A Review of The Empirical Literature. Psychological Bulletin, 141(3), 574-601.

Anderson, C., John, O. P., Keltner, D., \& Kring, A. M. (2001). Who Attains Social Status? Effects of Personality and Physical Attractiveness in Social Groups. Journal of Personality and Social Psychology, 81(1), 116-132.

Bartos, P., Rahman, A., Horak, J., \& Jacova, H. (2015). Education and Entrepreneurship in The SME Segment in Economic Transformation. Economics and Sociology, 8(2), 227-239.

Bernama. (2019). Only 40pct of Companies are Owned by Malays, Other Bumis - Hatta. Malaysiakini. https://www.malaysiakini.com/news/482933

Bollo, H., Bothe, B., Toth-Kiraly, I., \& Orosz, G. (2018). Pride and Social Status. Frontiers in Psychology, 9(1979).

Bosma, N., Hessels, J., Schutjens, V., Praag, M. van, \& Verheul, I. (2012). Entrepreneurship and Role Models. Journal of Economic Psychology, 33(2), 410-424.

Brewer, J., \& Gibson, S. W. (2014). Necessity Entrepreneurs: Microenterprise Education and Economic Development. In J. Brewer \& S. W. Gibson (Eds.), Necessity Entrepreneurs: Microenterprise Education and Economic Development. Edward Elgar.

Brown, D. J., \& Zeigler-Hill, V. (2017). Self-Esteem. In The Self at Work (1st Ed., p. 32). Routledge.

Cambridge University Press. (n.d.). Pride. Cambridge University. Retrieved January 4, 2022, from https://dictionary.cambridge.org/dictionary/english/pride

Cao, J., \& Smith, E. B. (2021). Why Do High-status People Have Larger Social Networks? Belief in Status-quality Coupling as a Driver of Network-broadening Behavior and Social Network Size. Organization Science, 32(1), 1-22.

Cherry, K. (2021). What Is Self-Esteem? Verywell Mind. https://www.verywellmind.com/what-is-self-esteem-2795868

Creswell, J. W. (2009). Research Design: Qualitative, Quantitative, and Mixed Methods Approaches. In SAGE Publications, Inc (3rd Ed.).

Crusius, J., \& Lange, J. (2017). How Do People Respond to Threatened Social Status? Moderators of Benign Versus Malicious Envy. In R. H. Smith, U. Merlon, \& M. K. Duffy (Eds.), Envy at Work and in Organizations (pp. 85-110). Oxford University Press.

Department of Statistics Malaysia. (2021). Graduates Statistics 2020. https://dosm.gov.my/v1/index.php?r=column/cthemeByCat\&cat=476\&bul_id=U1 ltVWpwNXRNRUR2NlhRSHZmenRMUT09\&menu_id=Tm8zcnRjdVRNWWlpWjRlb mtlaDk1UT09

Encyclopedia Britannica. (2019). Social Status. Britannica.Com. https://www.britannica.com/topic/social-status

Encylopedia. (2020). Introduction: Entrepreneurship. Encyclopedia.Com. https://www.encyclopedia.com/finance/encyclopedias-almanacs-transcripts-andmaps/introduction-entrepreneurship

Fairlie, R. W., \& Fossen, F. M. (2018). Opportunity versus Necessity Entrepreneurship: Two Components of Business Creation. IZA Discussion Paper, 11258.

Fershtman, C., Murphy, K. M., \& Weiss, Y. (1996). Social Status, Education and Growth. Journal of Political Economy, 104(1), 108-132.

Gabriel, D. I. (2014). Fundamental Aspects of The Entrepreneurship in The Contemporary Economic World. Annals - Economy Series, 4, 129-133.

Garaika, \& Margahana, H. (2019). Self Efficacy, Self Personality and Self Confidence on Entrepreneurial Intention: Study on Young Enterprises. Journal of 
Entrepreneurship Education, 22(1), 1-12.

Garcia-Lorenzo, L. (2018). The Invisible Entrepreneur: from Unemployment to Unstable Self-employment. LSE Business Review. http://eprints.lse.ac.uk/87246/

Global Entrepreneurship Research Association. (2018). Global Report 2017/18.

Gregg, A., Sedikides, C., \& Pegler, A. (2018). Self-Esteem and Social Status: Dominance Theory and Hierometer Theory? Encyclopedia of Evolutionary Psychological Science, 1-6.

Hamidon, S. (2009). The Development of Malay Entrepreneurship in Malaysia. Massey University.

Hamilton, R. T., \& Harper, D. A. (1994). The Entrepreneur in Theory and Practice. Journal of Economic Studies, 21(6), 3-18.

Hodzic, S. (2016). Increasing PhD Students' Employability by Focusing on The Academic Entrepreneurship. The Analysis of The Entrepreneurial Competences. Tuning Journal for Higher Education, 3(2), 347-387.

Ismail, N., Jaffar, N., \& Hooi, T. S. (2013). Self-employment Intentions Among the Universities' Students in Malaysia. Corporate Ownership and Control, 10(3), 456463.

Jha, M. (2016). Opportunity Entrepreneurs Are Key to Jobs and Growth. World Bank. https://blogs.worldbank.org/jobs/opportunity-entrepreneurs-are-key-jobs-andgrowth

K.Durkee, P., W.Lukaszewski, A., \& M.Buss, D. (2019). Pride and Shame: Key Components of a Culturally Universal Status Management System. Evolution and Human Behavior, 40(5), 470-478.

Kalden, J. N., Cunningham, J., \& Anderson, A. R. (2017). The Social Status of Entrepreneurs: Contrasting German Perspectives. The International Journal of Entrepreneurship and Innovation, 18(2), 91-104.

Kennedy, J. C., \& Mansor, N. (2000). Malaysian Culture and the Leadership of Organisations : A GLOBE Study. Malaysian Management Review, 35(2), 42-53.

Kennedy, J., Drennan, J., Renfrow, P., \& Watson, B. (2003). The Influence of Role Models on Students' Entrepreneurial Intentions. Queensland Review, 10(1), 37-52.

LibreTexts. (2021). Social Status. https://socialsci.libretexts.org/@go/page/8035

Mack, N., Woodsong, C., MacQueen, K. M., Guest, G., \& Namey, E. (2005). Qualitative Research Methods: A Data Collector's Field Guide. Family Health International.

Mahadea, D., \& Kaseeram, I. (2018). Impact of Unemployment and Income on Entrepreneurship in Post-apartheid South Africa: 1994-2015. The Southern African Journal of Entrepreneurship and Small Business Management, 10(1), 1-9.

Malebana, M. (2016). The effect of entrepreneurial role models on entrepreneurial intention in South Africa. Journal of Contemporary Management, 13(13), 90-116.

Mansor, T. R. T., \& Daud, Z. (2020). The Effect of Social Network on Malaysian MalayOwned SME Performance. Albukhary Social Business Journal, 1(1), 73-85.

Marzuki, S. Z. S., Kadir, M. A. B., Buyong, S. Z., \& Junid, J. (2016). Motivating Factors Influencing Business among Youth in Malaysia. ASEAN Entrepreneurship Journal, 2(2), 37-45.

Mcewan, G. (2020). The Rise of the Necessity Entrepreneur. https://www.linkedin.com/pulse/rise-necessity-entrepreneur-professor-garymcewan

Merriam, S. B. (2009). Qualitative Research: A Guide to Design and Implementation (2nd ed.). Jossey-Bass.

Mersha, T., Sriram, V., \& Hailu, M. (2010). Nurturing Opportunity Entrepreneurs in Africa: Some Lessons from Ethiopia. J. Global Business Advancement, 3(2), 155-175. 
Milanov, H. (2015). Social Status in Entrepreneurship. In Wiley Encyclopedia of Management. John Wiley \& Sons, Ltd.

Ministry of Education Malaysia. (2019). Laporan Kajian Pengesanan Graduan 2018.

Mirowsky, J., \& Ross, C. E. (2003). Education, Socioeconomic Status, and Health. In Education, Social Status, and Health (1st Ed.). Routledge.

Mohammed, F. (2016). What Makes a Career Prestigious? JSTOR Daily. https://daily.jstor.org/makes-career-prestigious/

Mondal, P. (2017). The Importance of Sociology to Society. https://www.yourarticlelibrary.com/sociology/the-importance-of-sociology-tosociety-1219-words/8490

Mukherjee, K. (2016). The Psychology of the Successful Entrepreneur. International Journal of Ad- Vanced Engineering and Management, Technical and Scientific Publisher, 1(1), 25-32.

Ngah, R., Rahman, A. Z. A. A., \& Buyong, S. Z. (2016). Entrepreneurial Self-efficacy and Entrepreneurial Intention of University's Students: The Impact of Entrepreneurial Learning. Asean Entrepreneurship Journal, 2(1), 64-73.

Nowiński, W., \& Haddoud, M. Y. (2018). The Role of Inspiring Role Models in Enhancing Entrepreneurial Intention. Journal of Business Research, 96, 183-193.

Pyakuryal, K. (2001). Weberian Model of Social Stratification - A Viewpoint. Occasional Papers in Sociology and Anthropology, 7, 14-25.

Razalli, N. L. Y. M., \& Kadir, M. A. B. A. (2021). Understanding the Sociological Aspects Impacting the Business Endeavour Among Bumiputera Graduates. Malaysian Journal of Social Sciences and Humanities, 6(12), 213-222.

Reynolds, P. D. (1992). Sociology and Entrepreneurship: Concepts and Contributions. Entrepreneurship Theory and Practice, 16(2), 47-70.

Rivai, H. A. (2012). Factor Influencing Student's Intention to be Entrepreneur: An Evidence from Indonesia Higher Education. ASEAN Entrepreneurship Journal, 12(1).

Rokhman, W., \& Ahamed, F. (2015). The Role of Social and Psychological Factors on Entrepreneurial Intention Among Islamic College Students in Indonesia. Entrepreneurial Business and Economics Review, 3(1), 29-42.

Rose, J. P., \& Vogel, E. (2017). Self-Esteem and Social Status. In Encyclopedia of Personality and Individual Differences (Zeigler-Hi). Springer, Cham.

Saputra, C. (2020). Social Status as a Nonverbal Language in Priyayi Society. Advances in Social Science, Education and Humanities Research, 509, 131-136.

Sarahyu, \& Chung, H. (2017). Unemployment and Depression: Investigating The Pathway With Latent Deprivation and Economic Deprivation Theories. Proceedings of ISER 67th International Conference, Beijing, China, July, 9-12.

Shanka, B. B. (2016). Unemployment Experiences of Young Graduates and their Attitudes Towards Business Startups in Micro and Small Enterprises ( MSEs ): A Lesson from Southern Ethiopia. Norwegian University of Science and Technology (NTNU).

Swatz, M. (n.d.). Repairing Job Identity Loss While Unemployed. Monster. Retrieved June 26, 2020, from https://www.monster.ca/career-advice/article/have-you-sufferedfrom-job-identity-loss

Tackey, N., \& Perryman, S. (1999). Graduates Mean Business: A Study of Graduate Selfemployment and Business Start-ups. In The Institute for Employment Studies Report 357.

Van Osch, Y., Zeelenberg, M., Breugelmans, S. M., \& Brandt, M. J. (2019). Show or Hide Pride? Selective Inhibition of Pride Expressions as a Function of Relevance of Achievement Domain. Emotion, 19(2), 334-347.

Wahlbeck, Ö. (2008). Entrepreneurship as Social Status: Turkish Immigrants' 
Experiences of Self-Employment in Finland. Migration Letters, 5(1), 53-62. 